\title{
Analysis
}

\section{Shortfalls of funding for general practice in deprived areas}

\section{INTRODUCTION}

In April 2019 the Haxby Group, through a contract tender process, acquired two surgeries in a deprived area of Hull, Yorkshire. These are specifically located in Calvert and Newington with approximately 10000 patients. This, in addition to six sites in York and three other sites in Hull, with centralised administrative services, make up the Haxby Group. The transformative process that has followed has highlighted many positive outcomes from the use of at-scale general practice and diversifying the workforce but has become increasingly hindered by funding deficits. In particular the use of the Carr-Hill formula and Quality and Outcomes Framework (QOF)-driven payments negatively impact a practice's ability to provide appropriate care in deprived populations.

The population served by this new contract is predominantly young (Figure 1). The area, like most of Hull, is especially high on the Index of Multiple Deprivation, scoring 43.7, compared with 28.1 at another Haxby practice in Hull and 10.4 in York. As is often seen in deprived areas, there is a high incidence of drug and alcohol misuse plus mental health problems. Alongside this, $9.0 \%$ of the patients are recorded with obesity and $55.9 \%$ as smokers. However, given the average age of the population, most chronic diseases have a prevalence below the clinical commissioning group (CCG) and national averages (Table 1).

\section{HEALTH INEQUALITY AND DEPRIVATION}

Public Health England data from 2016-2018 show life expectancies from birth for Hull to be 76.0 years for males and 80.2 years for females 179.6 years and 83.2 years respectively nationally). ${ }^{1}$ These figures have shown no improvement over the last decade, which is in keeping with the recent Marmot report that demonstrated this trend, particularly in deprived communities of the north. ${ }^{2}$ Using last year's data, the average age at death for these two sites in 2019 was 69.4 years for males and 79.1 years for females, which is in keeping with Hull CC data showing life expectancy to be lower in the more deprived areas. ${ }^{3}$

Records from these two Hull practices show $45.0 \%$ of deaths in a 6 -month period recorded with a malignancy as the primary cause of death; nationally this figure is $28.0 \%$ of all deaths. ${ }^{4}$ Previous studies have shown the north east of England to have higher

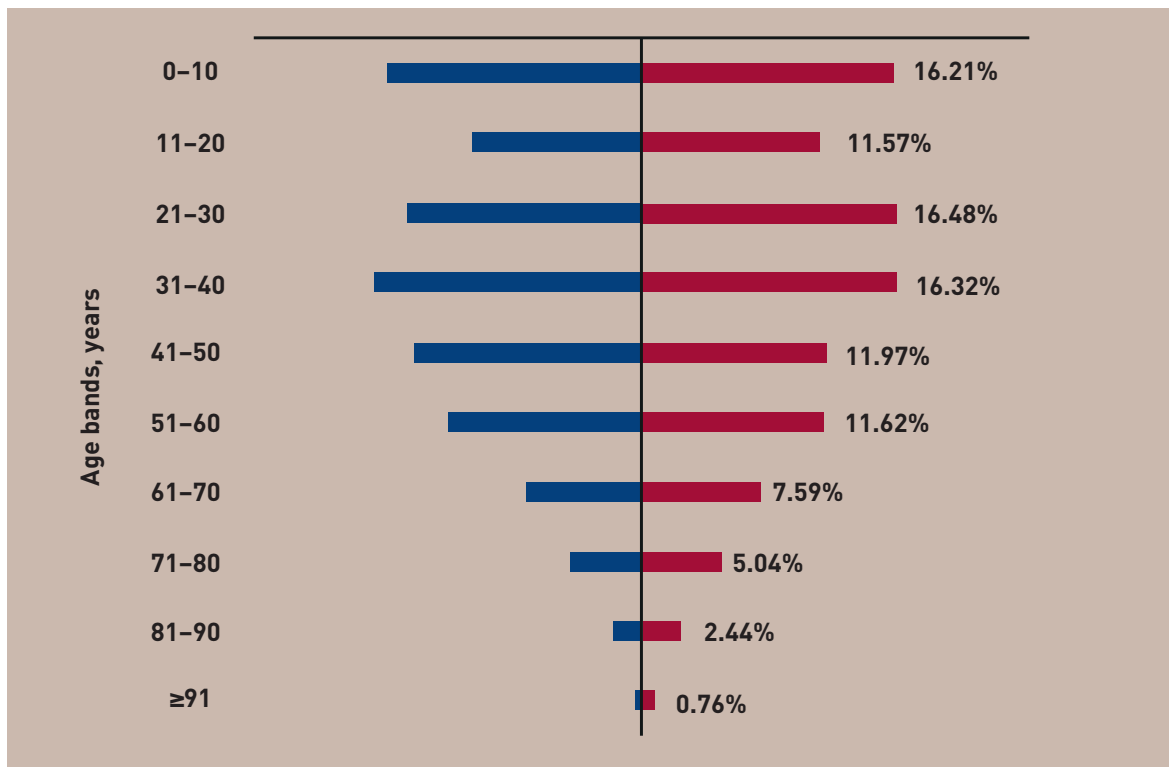

Figure 1. Patient age distribution in years of males (blue) and females (red) at Calvert and Newington in 2019.

incidences of cancer. ${ }^{5}$ Data from the cancer register of our Hull practices has shown an incidence of 18.2 per 1000 compared with 12.2 per 1000 in Kingswood (the least deprived area of Hull). Lifestyle factors such as smoking, alcohol consumption, and obesity are all known to be causative but late intervention and treatment likely also play a role.

Hart first described the inverse care law where good medical care tends to vary inversely with the need for it in the population served'. Historically at these practices there has been a high did not attend (DNA) rate and low numbers of performance indicators such as medication and chronic disease reviews, signifying the poor healthcare prevention and engagement for this population. The inaccessibility and lack of adaptation to services, partly due to inadequate funding alongside poor staff recruitment, has left a service where those in greatest need do not receive the primary care services required.

\section{WORKFORCE AND SYSTEM CHANGES}

To help address this there has been a workforce transformation at these sites. Having previously been predominantly staffed by locum GPs these sessions have been reduced, not only for cost benefit but also to allow more ownership and continuity of care for patients. This has largely been achieved but has been hindered by ongoing recruitment difficulties in Hull, with $10 \mathrm{GP}$ sessions per week still requiring locum cover currently. The strategy has also involved increasing the nursing staff and introducing primary care practitioners who are used throughout the other sites within the Haxby group with proven benefit.' This has resulted not only in improvements in appointment availability due to the diversified workforce but also dramatic increases in chronic disease reviews, most notably diabetes increasing from 7 to 220, plus 1155 more medication reviews (both comparing the same quarter in subsequent years to allow for seasonal differences). There have also been 227 fewer referrals to secondary care when comparing the same time periods.

Simultaneously there has been a reduction in the DNA rate, which is likely partly attributable to the second phase of change in June 2019 that brought in a GP-led triage system. The system redesign allows for more same-day appointments instead of predominantly pre-bookable appointments, as well as direction of patients to the most appropriate healthcare professional. There were 53 fewer DNA appointments with improvements across all age ranges when comparing the 6 months either side of the takeover. Therefore, reduced waiting times and easier access to healthcare professionals are benefiting this population who can often be hard to engage and comply with treatment.

\section{NEGATIVE IMPACTS OF FUNDING FORMULAS}

However, despite these positive results, ongoing difficulties have been faced 


\section{Table 1. Comparison of prevalence data for major comorbidities in Calvert and Newington, nationally, ${ }^{8}$ and Hull CCG ${ }^{8}$ for 2018/2019}

\begin{tabular}{lccc} 
& $\begin{array}{c}\text { Calvert and } \\
\text { Newington } \\
\text { Area }\end{array}$ & $\begin{array}{c}\text { National } \\
\text { prevalence, } \%\end{array}$ & $\begin{array}{c}\text { Hull CCG } \\
\text { prevalence, \% }\end{array}$ \\
\hline psevalence, \% \\
\hline Atrial fibrillation & 5.80 & 6.05 & 6.08 \\
\hline Cancer & 1.40 & 1.98 & 1.65 \\
\hline Cardiovascular disease primary prevention & 1.90 & 2.98 & 2.66 \\
\hline COPD & 1.20 & 1.13 & 1.42 \\
\hline Dementia & 2.40 & 1.93 & 2.81 \\
\hline Diabetes & 0.40 & 0.78 & 0.75 \\
\hline Heart failure & 6.81 & 6.93 & 7.42 \\
\hline Hypertension & 0.70 & 0.93 & 0.79 \\
\hline Mental health & 13.30 & 13.96 & 14.40 \\
\hline Palliative care & 1.20 & 0.96 & 0.97 \\
\hline Peripheral arterial disease & 0.40 & 0.40 & 0.28 \\
\hline Secondary prevention of coronary heart disease & 0.70 & 0.60 & 0.75 \\
\hline Stroke and transient ischaemic attacks & 3.00 & 3.10 & 3.69 \\
\hline
\end{tabular}

$C C G=$ clinical commissioning group. $C O P D=$ chronic obstructive pulmonary disease .

as research has shown the current flat distribution of funding in general practice does not allow for the increased complexity and higher workloads from serving deprived populations. ${ }^{9}$ The Carr-Hill formula has been used since 2004 to calculate basic core payments for practices. It was designed to compensate for different workloads by adjusting for factors such a population age and sex, list turnover, standardised mortality ratio, and rurality but not any meaningful measures of deprivation. Previous studies have already shown this model to adversely affect deprived populations as the adjustments poorly represent the needs of these populations. One such study demonstrated that, for each 10\% increase in the Index of Multiple Deprivation score, practice payments increased by only $0.06 \% .^{10}$ When the Carr-Hill formula is applied to these two practices in Hull it has led to a reduction in patient payments for the weighted data compared with the raw data. In quarter two post-takeover, this stood at a negative difference of 698 patients.

There are similar concerns regarding QOF-driven payments, which for most practices represent $8 \%$ of total income. ${ }^{11}$ QOF is prevalence driven and, as previously mentioned, these practices have comparably low chronic disease prevalence rates due to the young age of the population. A review of QOF has already stated that it is not promoting the aims of the Five Year Forward View, such as holistic and patient-centred care. ${ }^{11}$ This is felt even more so in deprived areas where this current model seems only to reward increasing chronic disease instead of promoting early intervention in highrisk populations to prevent it. This current system does not help to address the reported increasing income-related health inequalities that the UK is experiencing. ${ }^{12}$

\section{NEED FOR RE-EVALUATION}

Currently the changes made through this transformative process have had a positive impact on some performance indicators and health outcomes as well as improved patient satisfaction. However, the financial penalties of serving a deprived population are hindering further change and improvement while contributing to the existing health inequalities. Given recent parliamentary commitments for extra NHS funding it is now crucial that there is greater understanding of what different communities need so a more structured and integrated healthcare system can be delivered. We believe this involves re-evaluating the suitability of tools such as the Carr-Hill formula, which no longer serves its purpose.

Laura Castle,

Salaried GP, Haxby Group, York \& Hull.

\section{Melanie Bradshaw,}

Head of Business Intelligence, Haxby Group, York \& Hull.

\section{Thomas Patel-Campbell,}

GP Partner and Chief Clinical Information Officer, Haxby Group, York \& Hull.

\section{Michael Holmes,}

GP Partner, Haxby Group, York \& Hull; Vice Chair (Membership), Royal College of General Practitioners.

\section{John McEvoy,}

Managing Partner, Haxby Group, York \& Hull.

\section{Provenance}

Freely submitted; externally peer reviewed.

\section{ADDRESS FOR CORRESPONDENCE}

Laura Castle

Haxby Group, The Village, Wiggington, York

YO32 2LL, UK.

Email: laura.castle1anhs.net

\section{Competing interests}

The authors have confirmed no competing interests.

DOI: https://doi.org/10.3399/bjgp20X713357

\section{REFERENCES}

1. Public Health England. Life expectancies and causes of death. https://fingertips.phe. org.uk/profile/health-profiles/data\#page/0/ gid/1938132696/pat/6/par/E12000003/ati/201/ are/E06000010 (accessed 1 Oct 2020).

2. Marmot M. Health equity in England: the Marmot review 10 years on. BMJ 2020; 368 m693.

3. Hull City Council. Hull joint strategic needs assessment 2018. http://www.hullcc.gov.uk/ pls/hullpublichealth/assets/JSNA2018 c20. pdf laccessed 1 Oct 2020).

4. Cancer Research UK. Cancer statistics; https:// unw.cancerresearchuk.org/health-professional/ cancer-statistics/mortality (accessed 6 Oct 2020)

5. Office for National Statistics. Cancer registration statistics, England 2017. https://wnw.ons. gov.uk/peoplepopulationandcommunity/ healthandsocialcare/

conditionsanddiseases/bulletins/ cancerregistrationstatisticsengland/2017 laccessed 1 Oct 2020).

6. Hart JT. The inverse care law. Lancet 1971; 1(7696): 405-412.

7. Holmes M. Investing in a sustainable workforce. 2017. https://www.nuffieldtrust. org.uk/news-item/investing-in-a-sustainableworkforce (accessed 1 Oct 2020).

8. NHS Digital. Quality and Outcomes Framework interactive dashboard 2015-16 to 2018-19 https://digital.nhs.uk/data-and-information/ data-tools-and-services/data-services/ general-practice-data-hub/quality-outcomesframework-qof laccessed 6 Oct 2020).

9. Mclean G, Guthrie B, Mercer SW, et al. General practice funding underpins the persistence of the inverse care law: cross sectional study in Scotland. Br J Gen Pract 2015; DOI: https://doi. org/10.3399/bjgp15X687829.

10. Levene LS, Baker R, Bankart J, et al. Socioeconomic deprivation scores as predictors of variations in NHS practice payments: a longitudinal study of English general practices 2013-2017. Br J Gen Pract 2019; DOI: https:// doi.org/10.3399/bjgp19X704549.

11. NHS England. Report of the review of the Quality and Outcomes Framework in England. 2018. https://www.england.nhs.uk/wp-content/ uploads/2018/07/quality-outcome-frameworkreport-of-the-review.pdf (accessed 1 Oct 2020).

12. Jivraj S. Are self-reported health inequalities widening by income? An analysis of British pseudo birth cohorts born, 1920-1970. J Epidemiol Community Health 2020; 74(3): 255-259. 